\title{
DIFFICULTIES IN GEOGRAPHY TEACHING AND LEARNING IN THE ESL CLASSROOM IN ZIMBABWE
}

Erick Nyoni, Midlands State University, Zimbabwe

Vivian Manyike, University of South Africa

Eleanor Lemmer, University of South Africa

English second language (ESL) learners in secondary schools in Zimbabwe mediate learning through a second language. This is against best practice, which indicates that learning should be conducted in the learner's first language. ESL learners are at risk and expected to develop cognitive academic language proficiency (CALP) for academic achievement. Content area teachers need to capacitate ESL learners with CALP to make content comprehensible. Teachers who lack the requisite skills to develop the CALP skills of ESL learners fail to develop the discourse patterns that are attendant to the particular content area disciplines being taught. The study draws on Cummins' theory of a common underlying proficiency and Vygotsky's sociocultural theory to establish the difficulties encountered in geography teaching and learning in the ESL classroom. An ethnographic study investigated the teaching of CALP in geography to a selected form 3 class of ESL learners in Zimbabwe to address the research question: What difficulties are encountered in the teaching and learning of geography in an ESL classroom? Data were collected using teacher interviews and classroom observation. The research findings indicate the following: inadequate teacher preparation for the development of CALP among ESL geography learners; limited teacher accommodation of ESL learners' language needs; lack of a policy framework regarding the use of learners' first language during geography tuition; negation of the teacher's role in the development of geography discourse; and lack of skills in the use of instructional media to develop CALP. It is recommended that teachers be trained to develop CALP in content area instruction during pre-service or in-service training for them to assist ESL learners to comprehend content.

Keywords: cognitive academic language proficiency, interdependence hypothesis, common underlying proficiency, geography instruction, secondary schools, ethnography, Zimbabwe

\section{INTRODUCTION}

Insight into constraints faced in the teaching and learning of geography can be best understood through an understanding of the nature of cognitive academic language proficiency (CALP), an essential language proficiency skill required for academic success. The development of the CALP skills of English second language (ESL) learners in content area learning is critical to facilitate abstract thought processes during learning. Thus, language researchers are calling upon every teacher to be a language teacher in order to assist learners, particularly ESL learners, with the subject-specific vocabulary required in various subjects taught in schools (Carmela \& Shalini, 2014; Cummins, 2005; Grosser \& Nel, 2013; LaijaRodríguez, Ochoa \& Parker, 2005; Zwiers, 2013). Geography, for example, includes subjectspecific vocabulary that is new to learners as it is not used in daily conversation. Teaching geography content requires teachers to 'take' learners to the outside world or for teachers to create this world in their classrooms using CALP. Teachers who are without the requisite 
theoretical knowledge and instructional strategies to develop CALP in ESL learners fail to develop the discourse patterns that are attendant to geography (De Guzman, Olaguer \& Novera, 2017), which constrains the educational achievement of ESL learners. In Anglophone African countries, most ESL learners struggle to acquire adequate CALP for academic achievement due to the conditions under which English is taught and learned.

\section{PURPOSE OF THE STUDY}

The purpose of the study was to establish difficulties in geography teaching and learning in an ESL classroom in Zimbabwe. The study sought to answer the research question: What problems are faced in the teaching and learning of geography in an ESL classroom? The theoretical framework that mainly informed the study was Cummins' theory concerning CALP and related concepts. The choice of geography in studying constraints faced in an ESL classroom does not in any way raise the status of geography, but initiates an exploration of discourse on issues to do with language and learning in content area disciplines. Further studies can be carried out in other content area disciplines.

\section{LITERATURE REVIEW}

There are a number of studies on the constraints faced by ESL learners in content area teaching and learning, as exemplified by Duff (2001), Janzen (2008), Goldenberg (2008) and Gibbons (2012). From an ethnographic examination of ESL students with an Asian background, Duff (2001) examined issues confronting ESL students in mainstream content areas at secondary school level. The study revealed that, to succeed in class, students needed to participate in a variety of types of classroom discussion and reading and writing activities. They also needed a current knowledge of popular North American culture, mass media and newsworthy events, the ability to express a range of critical perspectives on social issues and to enter quick-paced interactions, and a great deal of confidence. Learners who were not capacitated to meet the discourse requirements of the content area would not participate meaningfully in classroom interaction.

Janzen (2008) examined current research on teaching English language learners in four content area subjects: history, mathematics, English and science. According to Janzen (2008), a number of overlapping concerns in the four content areas were evident, and the most frequently referenced was the centrality of language to learning. The language of academic texts, both those the students read and the ones they produce, has distinctive features and meanings that may present a contrast to the language used in informal spoken interaction. Janzen (2008) notes that academic language can differ from one discipline to another. Janzen (2008) concludes that academic uses of language as well as the meaning of individual words need to be explicitly taught for students to fulfil the genre discourse requirements privileged in academic settings and to understand the material they encounter.

Language can play a critical role in enabling learners to reach deeper levels of comprehension. Gibbons (2012) investigated how teacher-student talk in a content-based (science) classroom contributed to learners' language development. In Gibbons' (2012) study, two teachers were studied with regard to how they mediated between the students' current linguistic levels in English and their common-sense understandings of science on the one hand, and the educational discourse and specialist understandings of the subject on the other. The findings were that, through the teacher's mediation, students' contributions to the discourse of the classroom were progressively transformed into the specialist discourse of the school curriculum. The teachers' mediating role indicated how the teachers built linguistic 
bridges to span the difficulty, difference or distance between the language of the home and the language of school. Gibbons observes that, in content classrooms, the learning of science must go hand-in-hand with the development of a second language (L2), noting that classroom interactions are a major site for language development. The concerns by Duff (2001), Janzen (2008) and Gibbons (2012) are encapsulated by Goldenberg (2008), who indicates that ESL learners face a formidable task when they attend mainstream classrooms where English is the medium of instruction. The concern in the studies is that 'teaching ESLs is not an easy task for regular classroom teachers who have not received training in how to instruct ESLs' (Goldenberg, 2008). In Zimbabwe, English is a medium of instruction and it would be critical to understand difficulties faced by ESL learners in learning content.

In the context of Zimbabwe, no study is known to have investigated the difficulties faced in the teaching and learning of geography in an ESL classroom, and as such, this study aims at filling this gap. English is the conduit through which content is learnt in secondary schools from form 1 up to A-level. Form 1 refers to the first year of secondary education and A-level refers to the sixth year of secondary education. Although the use of the indigenous languages such as Shona and Ndebele is recommended from early childhood development A up to grade 7 as directed by the Amended Education Act of 2006 and the 2015 to 2022 curriculum framework, teachers often prefer English. The development of CALP skills is not explicitly emphasised in the curricula, including geography curricula, nor in teacher training at all levels in Zimbabwe (Nyoni, 2017). Further, geography performance in secondary schools is poor based on Zimbabwe Schools Examinations reports (Nyoni, 2017).

\section{THEORETICAL FRAMEWORK}

The theoretical framework that informed this study draws on Cummins' contributions to bilingual education. Cummins (2001) distinguishes between basic interpersonal communication skills (BICS) and CALP to explain the difficulties experienced by learners in understanding concepts in content areas. He notes a transition that learners undergo from the language of everyday use to the language used at school. Cummins (1999: 2) suggests that it takes two years for a child to develop peer-appropriate conversational fluency, but that it requires a considerably longer period of time (five to 10 years) to develop CALP. This may take longer in the African context where L2 learning environments are less favourable than in developed countries. Learners who only have BICS are incapacitated to understand concepts in school that are mediated by CALP.

As a strategy for developing CALP, content area teachers require knowledge of the impact of first language (L1) on L2 learning. Learners who are introduced to an L2 while their L1 is not well developed may suffer from what Cummins terms subtractive bilingualism. These learners are unable to attain CALP in both their L1 and L2. This results in semilingualism, which is having only partial knowledge or partial understanding of the language or the two languages in question, lacking mastery of either (Hinnenkamp, 2005; Lucchini, 2009). The importance of L1 development is based on the assumption that there is a common underlying proficiency which makes it possible for language gains in the L1 to be transferred to the L2. However, for this to occur a certain threshold needs to be reached. Cummins (1991: 72) suggests threshold levels of linguistic competence that bilingual children must attain both to avoid cognitive disadvantages and to allow the potentially beneficial aspects of becoming bilingual to influence their cognitive functioning. High thresholds are associated with academic advantages and low thresholds with academic disadvantages. Cummins (1981) posited the concept of common underlying proficiency (CUP) in reaction to a separate 
underlying proficiency, which proposes that language skills from two languages are stored separately and that there is thus no transfer across languages and no underlying proficiency that links L1 and L2. Cummins (2006: 4) further expresses the point that 'experience with either language can promote development of the proficiency underlying both languages, given adequate motivation and exposure to both either in school or in the wider environment'. Cummins (2000) clarifies the symbiotic relationship between a child's L1 and L2 in second language learning through a theoretical framework referred to as the interdependence hypothesis. Implied in the relationship is language transfer, meaning that language skills developed in the child's L1 facilitate learning in L2. Thus, a child who has mastered the basics of reading and thinking in his or her L1 will perform well upon entering a second language environment, such as a school. The child's L1 should therefore be used as a resource for learning.

In the process of teaching, tasks are given to learners and performance in the tasks is then gauged. A critical strategy for a content area teacher in developing CALP is the ability to determine the extent of cognitive engagement required of the learner. Tasks can be cognitively demanding or cognitively undemanding depending on whether context is embedded or reduced. In the geography classroom, dealing with weather without the use of peripheral learning such as charts or demonstrations can be cognitively demanding because context is reduced. The same lesson can be taught using charts, diagrams or visuals, and the task will not be that cognitively demanding because context is embedded. Lessons driven by demonstrations, science experiments and lessons with audio-visuals are context-embedded while cognitively demanding. Tasks that are context-reduced and cognitively undemanding are telephone conversations, following a friend's to-do list in geography and written instructions. Tasks that are context-reduced and cognitively demanding are reading and writing standardised tests - most content classes are examples of cognitively demanding and context-reduced tasks. Using the differences between cognitively demanding and cognitively undemanding tasks and knowledge of the task difficulty framework are important for teachers to help learners strategise how to develop the CALP skills of ESL learners (Cummins, 2000).

\section{METHODOLOGY}

To address the research question, What difficulties are encountered in the teaching and learning of geography to an ESL classroom?, a classroom-based ethnography was undertaken in a form 3 geography class at a selected English medium secondary school in a high-density suburb in Gweru, Midlands Province, Zimbabwe. The sample comprised 34 ESL geography learners and a female geography teacher. The learners were either Shona or Ndebele L1 speakers. The geography teacher held a post A-level diploma in education and a Bachelor of Education degree, majoring in geography. She had 23 years' experience of geography teaching and 13 years' experience of assessing national Ordinary Level geography examination papers. The Ordinary Level examination comes after four years of secondary education. The teacher was a Shona L1 speaker with English as an L2.

This paper is part of a larger study. Only findings from the initial interview with the teacher and classroom observations of 24 lessons over a six-week period are given in this paper, with the aim of determining the constraints faced in the teaching and learning of geography in an ESL classroom. The interview with the teacher was an initial interview (an interview carried out with the teacher before the classroom observations started).

The interview was audio recorded and transcribed. Field notes were made during observation. The data were analysed using qualitative inductive data analysis. This entailed creating codes 
of meaning, which were later organised into chunks of meaning (Bhengu \& Myende, 2015) and presented as themes. Ethical clearance was obtained from the University of South Africa and permission for the research was granted by the Zimbabwean Ministry of Education, Arts, Sports and Culture. Written consent was obtained from the teacher and the learners' parents, and assent was obtained from learners. Consent was subject to voluntary participation, the freedom to refuse information or to withdraw from the research at any time, the use of pseudonyms to protect anonymity and the non-disclosure of information that could lead to the disclosure of identity (Silverman 2015:158).

\section{RESULTS}

Five themes emerged from the interview and observation data: limited teacher accommodation of ESL learners' needs; lack of a policy framework in use of learners' L1 during geography tuition; teacher's negated role in the development of geography discourse; and a lack of skills in the use of instructional media to develop CALP.

\section{Inadequate teacher preparation for the development of CALP in geography}

The results indicate that the teacher did not undergo any explicit training on the development of learners' CALP skills in geography during pre- or in-service teacher training. The teacher stated:

The teaching of CALP skills was integrated in the general training. It was not done separately.

I wouldn't say we were taught specific strategies to develop Geography language.

Direct instruction of CALP development skills under methods of teaching geography did not take place during teacher training, though mastery of the subject matter was enhanced. This implies that there was adequate provision of content knowledge, but little attention on teaching strategies that enhanced the development of CALP in learners. The teacher stated:

As you know that each subject has got its own language, its own jargon as means of teaching. I remember very well even at teachers' college we were taught geographical language terms or these were highlighted as we went along.

Thus, CALP development strategies were not explicitly taught during teacher training. This constrains the learning of geography in an ESL-mediated classroom, considering that ESL learners are at risk and need instructional interventions to capacitate them with adequate levels of CALP. A knowledge gap on specific strategies for the development of CALP was noted. This gap could have been filled by an examination of Cummins' contributions on bilingual education, where a teacher develops awareness that ESL learners require help to close the gap between BICS and CALP. Inability to develop learners' CALP skills results in learners' inability to discuss the abstract thought processes in discourse patterns that are peculiar to the subject. Zwiers (2013) and Cummins (2013) clearly indicate that learners' educational attainment is constrained by poor CALP skills.

The teacher's inability to teach CALP skills can therefore be said to be a reflection of inadequate teacher training. During lesson observation, the teacher endeavoured to explain difficult and unfamiliar terms by highlighting them and explaining these words during lesson presentation. However, such explanations were inadequate in most cases, resulting in learners 
memorising the information without actually understanding the content they were learning. For secondary ESL learners to understand geography content, they require subject-specific CALP skills (Cummins, 1978).

\section{Teacher's accommodation of learners' $L 1$ and L2 during geography tuition}

Results from the interview with the teacher indicate that the teacher lacked the awareness that learners' L1s are a resource for learning. The form 3 geography learners in this study were predominantly from two linguistic backgrounds, namely Shona and Ndebele. The geography teacher stated:

The learners come from different linguistic backgrounds since Midlands province is predominantly inhabited by Shona and Ndebele speakers, so we have Shona and Ndebele speakers in the class ... those who are Ndebele speakers may also be fluent in Shona and the reverse is also true ... but English is the medium of instruction in the school.

Although learners had been using English as a medium of instruction from grade 4, they were not proficient in English. The teacher said:

Learners are poorly equipped to use English.

Their limited English is shown when they are asked to give explanations.

There are a lot of corrections that are made in their exercise books.

This situation placed linguistic demands on the teacher and the learners with regard to the development of their CALP skills. She admitted that learners found it difficult to grasp geography concepts in English. She commented: 'They struggle to articulate concepts during learning since learning is mediated in a language that is not their L1.'

The learners who participated in this study only used their L1 as a medium of instruction during the first four years of schooling. They transitioned to English as a medium of instruction in grade 3, before they had acquired the necessary CALP in their L1 to cope with the school curriculum. Most learners came from working-class backgrounds with limited linguistic enrichment. As these learners had not attained the required threshold to transfer the cognitive skills gained in their L1 to L2 learning, they experienced problems when they were expected to provide cognitively demanding and context-reduced explanations in geography. Although most form 3 geography learners had acquired BICS in English, this surface fluency was not enough to cope with the school curriculum (Gallagher, 2008:37). These learners needed CALP skills in order to learn geography efficiently. A teacher would therefore be required to be responsive to the language requirements of the learners to capacitate them with CALP relevant to the discourse patterns in geography.

The teacher did not encourage the use of L1 during lessons. She said: 'I do not allow any use of Shona by the learners except on rare occasions with slow learners.' She also felt that the use of L1 would be time-consuming. She said:

You would find that if I would allow them to think in Shona and give answers in Shona I think personally as a geography teacher, a secondary school teacher, high school teacher I don't have time for that. 
The teacher was unaware of the relationship between the learners' L1 and L2 (Birch, 2014; Goodrich, Lonigan \& Farver, 2013). Not allowing learners to use their L1 as a resource for learning would obviously constrain content area learning. These geography learners would benefit from a teacher who allows them to use their L1 to discuss content during group work. Once the content has been grasped, learners will find it easier to present it in English and their learning will be enhanced. Kioko (2015) supports the use of learners' home language in order to provide learners with an opportunity to be actively engaged in the learning process.

The geography teacher appeared to be more concerned with the examinations than learners' understanding of the content, as illustrated by these remarks. She stressed: 'Geography is a technical subject whose examination is to be written in English.' She felt that the use of learners' L1 during a geography class would hinder learning, since learners were not allowed to use L1 during examinations. She said: 'I do not want any Shona to intrude in the learning of geography because learners will fail to express themselves in the examination.'

A contradiction was noted, though, between data gathered during the initial teacher interview and what later transpired in the classroom, as code-switching manifested during the operationalisation of lessons.

\section{Teacher's use of code-mixing during geography tuition}

Although the teacher stated that she did not encourage the use of L1s (Shona and Ndebele) by learners in the classroom, observation results indicated that she herself used code-mixing extensively during geography lessons, a common teaching practice in Zimbabwean schools (Makokoni \& Makoni, 2011; Nhemo, 2015). Contradictions in the teacher's expectations on what language should be used by learners and her operationalisation of lessons, where codeswitching manifested, constrained learning in the ESL-mediated classroom as teaching would be done from an uninformed point of view.

The transcription of lessons observed during this study demonstrated that English was the dominant language, and Shona appeared to be the embedded language (Olson, 2016). An example of teacher code-switching was seen in a lesson on cyclones, which could be described as context-reduced and therefore cognitively challenging (Cummins, 2000). The lesson was made up of terms that were not found in the language of the home, and therefore presented a cognitively demanding task that required an understanding of related terms and vocabulary. Fearing confusion between cyclones and anticyclones, the teacher intervened by code-mixing and operated at an intra-sentential level by focusing on the word cyclone, saying 'Handina kuti anti ndati cyclone' ['I did not say anti, I said cyclone']. According to Cummins (1984), this exemplifies the transfer of metacognitive and metalinguistic strategies. The teacher noted the problem at a semantic level. The use of 'anti-' as affixation to form an opposite has no equivalence in Shona or Ndebele. The teacher also used alternative words in Shona which mean the same as a whirlwind, as indicated by 'whirlwind moziva chamupupuri'. The teacher used code-mixing to find parallel meanings in the matrix and embedded language, as exemplified by 'Class, ngatitarisewopa chalk board meaning ye the word gale G-A-L-E hatina kumboishandisa handiti tinoreva strong wind, fast wind.' ['Class let us look at the chalkboard and find the meaning of the word gale, spelled G-A-L-E. We never used it right. It means strong wind, fast wind. ']

Code-mixing was also used to determine the learners' pre knowledge of the topic. The teacher asked the learners, 'Wakambonzweyi kana wakambowonei, wakamboverenga nezve cyclone hamusati?' ['What have you heard or what have you seen? What have you read about 
cyclones?']. Similarly, in another lesson on landforms due to wind erosion, code-switching was used by the teacher to develop CALP. For learners to understand the concept of semiarid, the teacher focused on Shona synonyms for 'semi', using zviri pakati napakati [average] and zvisirikuma [extremes]. In explaining 'sparse', the teacher said 'zvimiti pano naapo. Togona kuwana muti apo umwe tomuwana kure' ['a tree here and a tree there']. This was an application of the CUP (Cummins, 1989) where both the matrix language and the embedded language were used as resources for learning.

In using code-mixing, and mindful of the fact that examinations are written in English, English remained the matrix language and Shona remained the embedded language in the lessons observed. This illustrated the application of the CUP (Cummins, 1989) where both the matrix language and the embedded language were used as resources for learning. The use of learners' L1s to scaffold learning is an acceptable and common practice in multilingual societies; in a very subtle way, additive bilingualism is being implemented and learners' identities are affirmed by the teacher (Cummins, 2013). Vygotsky proposes the theory of scaffolding, which entails building on what students already have after identifying their zone of proximal development.

\section{Teacher's negated role in the development of geography discourse competencies}

The results indicate that the teaching and learning of geography were constrained by the teacher's perception in that she did not in any way view herself as contributing to the teaching of the language or discourse of geography. There is no way content can be taught without language and conversely, language cannot be taught without looking at content. The teacher's perception of her role in developing the discourse competencies in geography is contrary to views by Ness (2009), Fisher and Frey (2014) and Fang (2014), who view the content area teacher's role as teaching language in the content area discipline. The findings indicate that the teacher negated her role with regard to language teaching in her geography classroom. She maintained that language teaching should be done at primary school level only, and as such, she did not view herself as a language teacher. This was confirmed by her comments when asked about her role in assisting learners with language-related matters:

I think it is in primary education, it is in basic education so it is the primary level where they are supposed to understand English or maybe develop this other language.

She regarded language proficiency as a separate responsibility that lay with the language teachers. In this regard she said, 'I am not a language specialist so I don't teach language but content.' This is contrary to Cummins' (2013) emphasis on the need for a language-focused teaching approach. The finding is also in line with the school's lack of policy in teaching English across the curriculum. Such a policy would make all teachers aware of their role in enhancing their learners' language proficiency skills while teaching various content disciplines. On dealing with the technical terms during the geography lesson, the teacher said the following:

I don't explain terms in isolation. I define them as we proceed. If it is a term, if it is a concept that needs definition, it gets clearer as I teach. I expect learners to understand the terms as we go along. I don't put aside time to particularly deal with key terms.

From the data above, the teacher indicated that she was practising what she experienced at college, but trends change and teaching requires following new trends. Her experience should have given her insight that teaching ESL learners puts language demands on the teacher. 
Content area teaching does require explicit instruction on vocabulary items, without which learners will not be able to think about abstract concepts in their learning.

\section{Scaffolding through the use of instructional media}

The patterns of chalkboard use in the development of CALP were observed. There was regular use of the chalkboard. Figures 1 and 2 exemplify chalkboard use and are representative of how the chalkboard was generally used by the teacher during the 24 geography lessons observed.

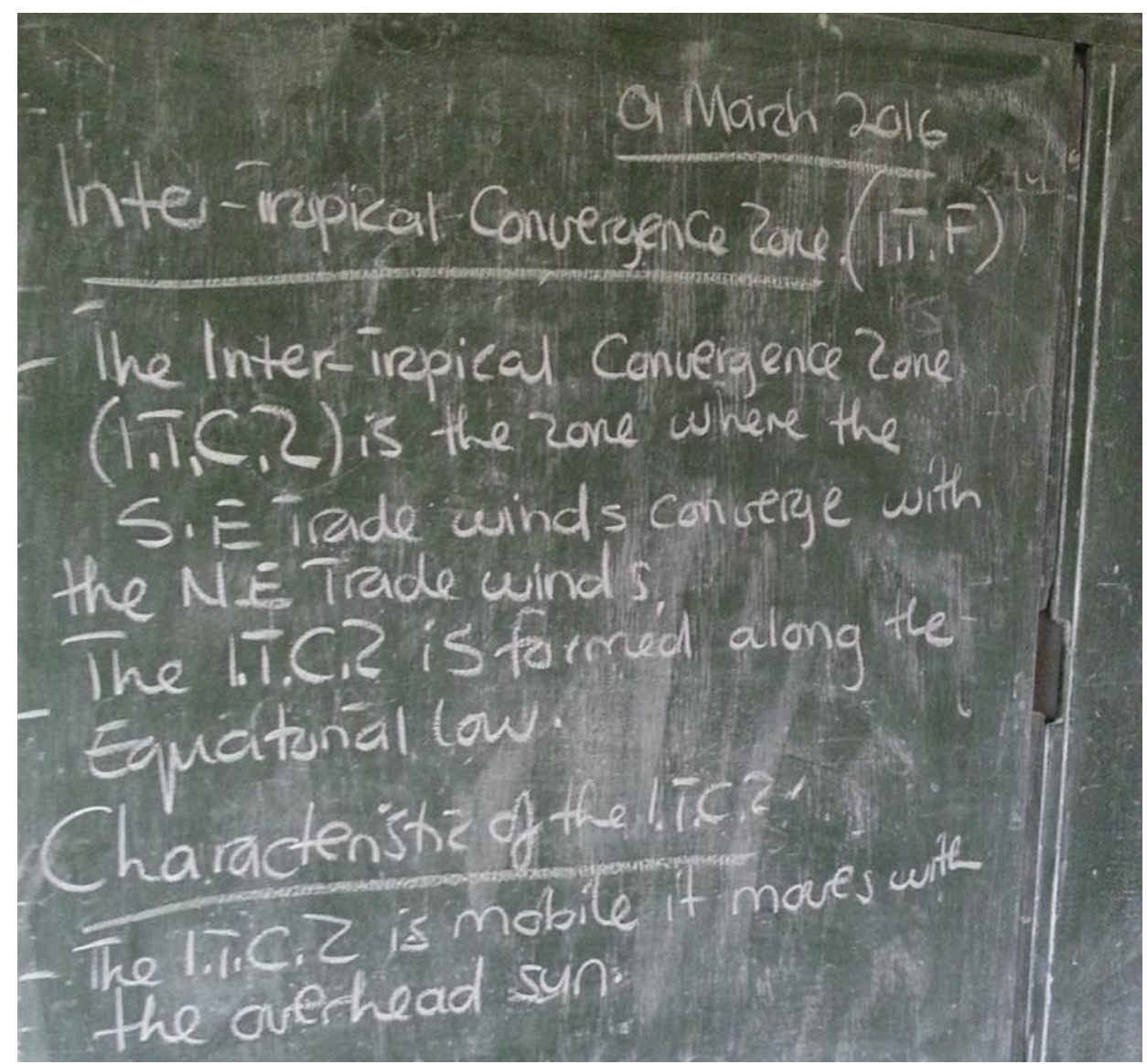

Figure 1: Chalkboard work on intertropical convergence zone

The results indicate that teaching and learning of geography can be constrained by the poor use of instructional media that does not advance the development of CALP in the learning of geography. The chalkboard offers many opportunities for the development of CALP skills. The teacher could have created a vocabulary corner where critical vocabulary is made prominent, but this was not the case in any of the lessons observed. Key vocabulary for geography as a discipline could also be made prominent by graphic organisers that are compatible with expository patterns in the texts used by learners. There were no cases of the use of graphic organisers in the lessons under observation. Graphic organisers are beneficial for ESL learners because they represent the main idea and other content visually with just a few words (Kareva \& Echevarria, 2013).

Figure 2 provides an illustration of how the teacher tried to develop concepts during a lesson on tropical cyclones. Again, the teacher failed to use graphic organisers on chalkboard work, which constrained learning. 


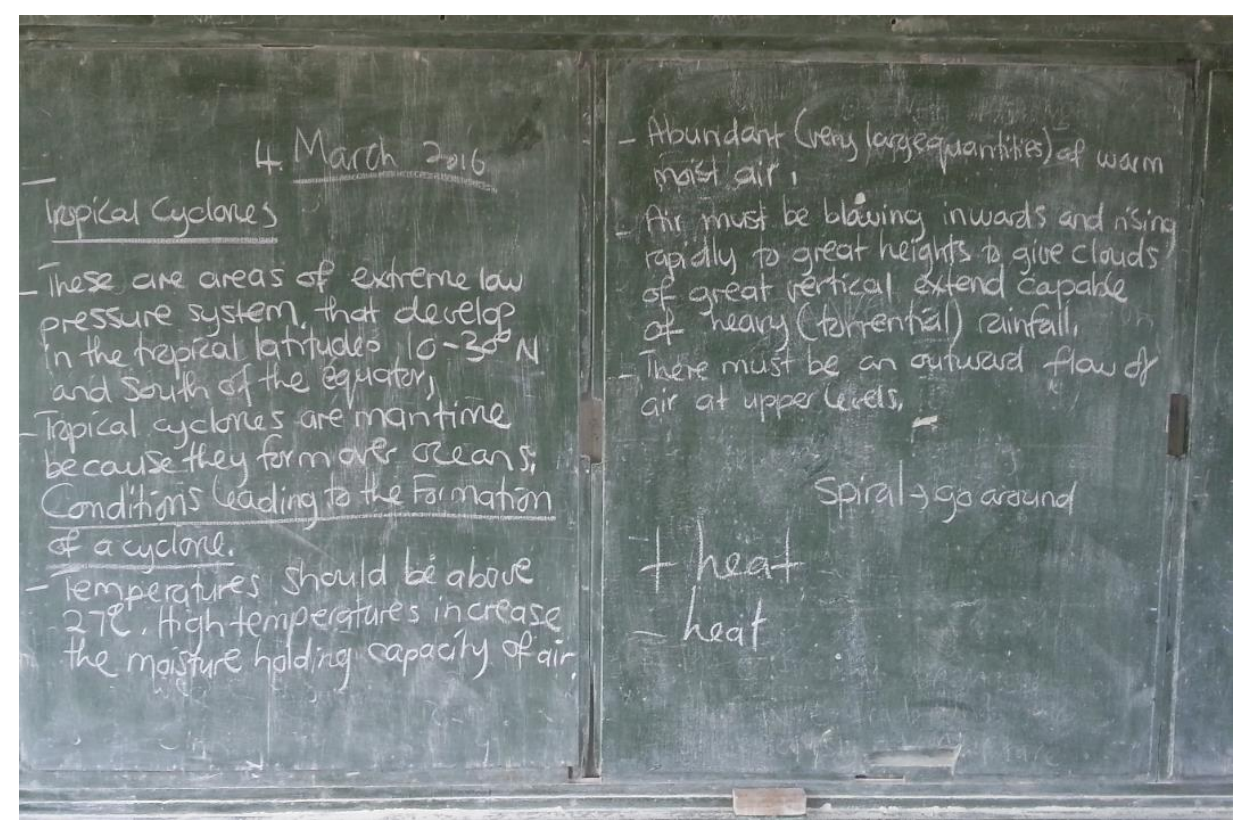

Figure 2: Chalkboard work on tropical cyclones

The syllabus states that learners should learn skills of graphicacy, which is described as the educated counterpart of the visual-spatial aspect of human intelligence and communication. Graphicacy is seen as fundamental in geography, along with literacy, articulacy and numeracy, since maps, diagrams, photographs and other spatial documents are the tools of graphicacy as well as the basis of geography (Balchin, 2013). Much of the data in geography are collected from the field and made visual for easier interpretation. The design of instructional media should be informed by graphicacy so that the instructional media are compatible with how information is presented in the texts. Instructional media can be used to scaffold learning if the teacher uses graphic organisers or content maps that can help to make input comprehensible and assist learners to store information in a systematic way that will facilitate the retrieval of this information (Brown, 2010:187). The use of frameworks such as semantic mapping can help learners in the development of CALP, since information will be clearly organised.

\section{CONCLUSIONS AND RECOMMENDATIONS}

This study focused on the difficulties encountered in the teaching and learning of geography in an ESL classroom in Zimbabwe. Data were gathered through an initial interview with the teacher and classroom observations. The analysis of the data revealed that the teacher did not have explicit training that enabled her to develop CALP in the learning of geography, which constrained the comprehension of abstract thought processes in the subject. The study established that the teacher was not responsive to the language backgrounds of the learners. A teacher who has knowledge of the learners' linguistic background is better placed to help learners approximate towards the levels of academic language proficiency that are necessary for the abstract thought processes found in the learning areas. The study results revealed that the geography teacher had an ambiguous approach to code-mixing during geography teaching. Although she discouraged learners from using their L1, mainly because it would jeopardise their performance in the examination, which was in their L2, the teacher made extensive use of code-mixing with one language, Shona, during her tuition. What the teacher needs to do is to accept that L1 is a resource and code mix in an informed way, not in a 
tentative way as indicated by the contradictions in the expectations and operationalisation of lessons.

\section{Implications of the study}

Based on the findings of the study, the authors make the following recommendations:

\section{Recommendations for schools}

The authors recommend that schools focus on the explicit instruction of geography discourse competencies for learners to be able to think about, read, write, listen to and speak about geography in a register that is peculiar to the discipline. To prevent confusion and to regularise the development of appropriate discourse competencies, schools should devise policies on language across the curriculum that give an operationalising framework with regard to how language should be developed in the teaching of content areas.

\section{Teacher education and training}

Universities and teacher training colleges should introduce modules or courses on CALP capacitation in order to teach both college and university students how to develop their own CALP skills and those of the learners that they are going to teach. There should be in-service training for content area teachers through workshops to capacitate them with CALP teaching skills.

\section{L1 as a resource for learning}

The authors recommend that the learners' L1 should be used during learning in the ESL classroom for effective learning to take place. In addition, code-mixing and switching between the medium of instruction and the learners' L1 should be accepted as a strategy to make content comprehensible.

\section{Further research}

Further research should be carried out in other content area disciplines so that more insight can be gained on constraints encountered in teaching ESL learners.

\section{REFERENCES}

BALCHIN, WGV. 1972. Graphicacy. Geography, 57:185-195.

BHENGU, TT \& PE MYENDE. 2015. Traversing metaphoric boundaries between schools and their communities: an ethnographic study of a rural school. Journal of Social Sciences, 43(3):227-236.

BIRCH, BM. 2014. English L2 reading: getting to the bottom. London: Routledge.

BRIGUGLIO, C \& S WATSON. 2014. Embedding English language across the curriculum in higher education: a continuum of development support. Australian Journal of Language and Literacy, 37(1):67-74.

BROWN, CL. 2007. Strategies for making social studies texts more comprehensible for English-language learners. The Social Studies, 98(5):185-188.

CUMMINS, J. 1979. Linguistic interdependence and the educational development of bilingual children. Review of Educational Research, 49(2):222-251. 
CUMMINS, J. 1981. Bilingualism and minority-language children. Toronto: The Ontario Institute for Studies in Education.

CUMMINS, J. 1986. Empowering minority students: a framework for intervention. Harvard Educational Review, 56(1):18-37.

CUMMINS, J. 1989. A theoretical framework for bilingual special education. Exceptional Children, 56(2):111-119.

CUMMINS, J. 1991. Interdependence of first- and second-language proficiency in bilingual children. In E. Bialystok (Ed.), Language processing in bilingual children (pp. 70-89). New York: Cambridge University Press.

CUMMINS, J. 1999. Alternative paradigms in bilingual education research: does theory have a place? Educational Researcher, 28(7):26-41.

CUMMINS, J. 2000. Language, power and pedagogy: bilingual children in the crossfire. Clevedon: Multilingual Matters.

CUMMINS, J. 2005. A proposal for action: strategies for recognizing heritage language competence as a learning resource within the mainstream classroom. Modern Language Journal, 89(4):585-592.

CUMMINS, J. 2013. Rethinking monolingual instructional strategies. Available from http://www.aclacaal.org/wp-content/uploads/2013/08/7-vol-10-no2-art-cummins.pdf [Accessed: 4 February 2016].

CUMMINS, J \& R MULCHAY. 1978. Orientation to language in Ukrainian-English bilingual children. Child development. 49(4):1239-1242.

DE GUZMAN, MD, L OLAGUER \& EGD NOVERA. 2017. Difficulties faced in teaching geography lessons at public secondary schools division of Zambales, Philippines. Available from http://www.iosrjournals.org/iosrjhss/papers/Vol.\%2022\%20Issue9/Version-7/I2209076470.pdf [Accessed: 13 December 2017].

DUFF, P. 2001. Language, literacy, content, and (pop) culture: challenges for ESL students in mainstream courses. Canadian Modern Language Review, 58(1):103-132.

FANG, Z. 2014. Preparing content area teachers for disciplinary literacy instruction: the role of literacy teacher educators. Journal of Adolescent \& Adult Literacy, 57(6):444-448.

FISHER, D \& N FREY. 2014. Content area vocabulary learning. The Reading Teacher, 67(8):594-599. DOI: https://doi.org/10.1002/trtr.1258

GALLAGHER, E. 2008. Equal rights to the curriculum: many languages, one message. Clevedon: Multilingual Matters.

GIBBONS, P. 2003. Mediating language learning: teacher interactions with ESL students in a content-based classroom. TESOL Quarterly, 37(2):247-273.

GONDO, R, S MUTOPA, T MANGWANDA \& OD KOLAWOLE. 2017. Poor performance in the advanced level geography: a case of four high schools in Hurungwe District, Mashonaland West Province, Zimbabwe. Lonaka Journal of Learning and Teaching, $8(1): 16-34$.

GOODRICH, JM, CJ LONIGAN \& JM FARVER. 2013. Do early literacy skills in children's first language promote development of skills in their second language? An experimental evaluation of transfer. Journal of Educational Psychology, 105(2):414.

GROSSER, MM \& M NEL. 2013. The relationship between the critical thinking skills and the academic language proficiency of prospective teachers. South African journal of education, 33(2):1-17.

JANZEN, J. 2008. Teaching English language learners in the content areas. Review of Educational Research, 78(4):1010-1038. 
KAREVA, V \& J ECHEVARRIA. 2013. Using the SIOP model for effective content teaching with second and foreign language learners. Journal of Education and Training Studies, 1(2):239-248.

KIOKO, A. 2015. Why schools should teach young learners in home language. Available from https://www.britishcouncil.org/voices-magazine/why-schools-should-teach-young-learners-homelanguage [Accessed: 13 December 2017].

KRASHEN, SD. 1982. Principles and practice in second language acquisition. Oxford: Pergamon Press.

LAIJA-RODRÍGUEZ, W, SH OCHOA \& R PARKER. 2006. The crosslinguistic role of cognitive academic language proficiency on reading growth in Spanish and English. Bilingual Research Journal, 30(1):87-106.

LEMMER, EM \& TV MANYIKE. 2012. Far from the city lights: English reading performance of ESL learners in different types of rural primary school. Per Linguam, 28(1):16-35.

LUCCHINI, S. 2009. Semilingualism: a concept to be revived for a new linguistic policy? In Linguistic identities, language shift and language policy in Europe. Leuven-Paris: Orbis/Supplementa.

MANYIKE, TV \& EM LEMMER. 2014. Research in language education in South Africa: problems \& prospects. Mediterranean Journal of Social Sciences, 5(8):251.

MANYIKE, TV. 2013. Bilingual literacy or substantive bilingualism? L1 and L2 reading and writing performance among grade 7 learners in three township schools Gauteng Province, South Africa. Africa Education Review, 10(2):187-203.

MANYIKE, TV. 2014. The writing skills in second language of learners from a rural primary school in South Africa. Studies of Tribes and Tribals, 12(1):61-69.

NESS, MK. 2016. Reading comprehension strategies in secondary content area classrooms: teacher use of and attitudes towards reading comprehension instruction. Reading Horizons, 49(2):5.

NYONI, E. 2017. Intervention strategies for the development of cognitive academic language proficiency in the instruction of geography in Zimbabwean secondary schools. Pretoria: University of South Africa.

OLSON, DJ. 2016. The impact of code-switching, language context, and language dominance on suprasegmental phonetics: evidence for the role of predictability. International Journal of Bilingualism, 20(4):453-472.

SILVERMAN, D. 2015. Interpreting qualitative data. London: Sage.

SINGO, J. 2014. Code-switching in doctor-patient communication. Nawa: Journal of Language \& Communication, 8(1).

VIRIRI, E \& M VIRIRI. 2013. The prevalence of code-switching in secondary schools where English is the official medium of instruction: a case study of Buhera South District. International Journal of Academic Research in Progressive Education and Development, 2(1).

VYGOTSKY, LS. 1986. Thought and language (revised ed.). Cambridge, MA: MIT Press.

ZWIERS, J. 2007. Teacher practices and perspectives for developing academic language. International Journal of Applied Linguistics, 17(1):93-116. 


\section{BIOGRAPHICAL NOTES}

Erick Nyoni is a Senior Lecturer in the Department of Applied Education at the Midlands State University in Zimbabwe and is interested in research on language and learning.

Prof Manyike is a Chair of the Department of Language Education Arts and Culture at UNISA in the college of Education. Her area of specialization is in English second language teaching and multicultural/ bilingual education.

Eleanor Lemmer is professor emeritus, College of Education, University of South Africa. Her area of specialization is parent-school partners and linguistic diversity in schooling in South Africa. 